\title{
Los recursos culturales del Parque Natural Sierra Norte de Sevilla
}

Rafael Pérez de Guzmán Puya Licenciado en Biología

Juan Molina Sánchez

Intérprete Informador

\section{Resumen}

En los pueblos que pertenecen a la Sierra Norte de Sevilla, la historia ha ido dejando su huella, desde la prehistoria hasta los tiempos más recientes. El recorrido realizado por cada uno de ellos nos permite encontrarnos con un patrimonio cultural muy rico y variado gracias, entre otros elementos, a las personas que viven en ellos.

\section{Palabras clave}

Pueblos / Sierra Norte de Sevilla/ Patrimonio Cultural / Ermitas / Castillos / Prehistoria / Celtíberos / Romanos / Árabes

\section{Almadén de la Plata}

En este pueblo existe presencia humana desde el Neolítico. Fenicios y griegos explotaron sus riquezas de mármol y plata, que con los romanos -cuando se llamaba lluria- llegaron al auge, como demuestra un epígrafe alusivo a un pagus marmorarius. Con los árabes es denominada Al-Medín (la mina). Fernando III dio a la población la Carta Puebla, otorgando con ello el derecho a ostentar en el escudo el castillo y el león de las armas reales. Participaron los almadenenses en la toma de Granada, con tanto empeño que los Reyes Católicos la privilegiaron con el título de leal. Muchos voluntarios partieron hacia la batalla de Bailén contra la tropa francesa.

\section{Alanís}

Hoy día, Almadén ofrece un paseo por la historia, que empieza en la cueva de los Covachos. Su entrada está obstruida con bloques de mármol, por su anterior uso como cantera; es larga, bien conservada en su interior y con varias salas individualizadas. En la entrada se aprecian unas marcas en el techo que quizás sean restos de pinturas rupestres. Además de la cueva, hay dos necrópolis dolménicas: Cañalazarza y los Castillejos.

La Iglesia de Santa María de Gracia, del siglo XVI, fue construida, entre otros, por los prestigiosos Vermondo Resta y Hernán Ruiz II. Su espléndido retablo recoge esculturas de santos del siglo XVIII, el Cristo del Crucero (XVI) y una Inmaculada de finales del siglo XVII. La orfebrería de esta iglesia cuenta con una cruz de plata del siglo XVII y un cáliz del mismo material del siglo XVIII.

De su arquitectura civil destaca el Ayuntamiento, del siglo XVIII, utilizado primero como hospital y luego como ermita.

\section{Alanís}

De origen romano, la conocida como Al-Baniz (tierra próspera) con los árabes, está dominada por un castillo de origen árabe, reestructurado en 1392. La conquista Fernando III en 1249, meses después que

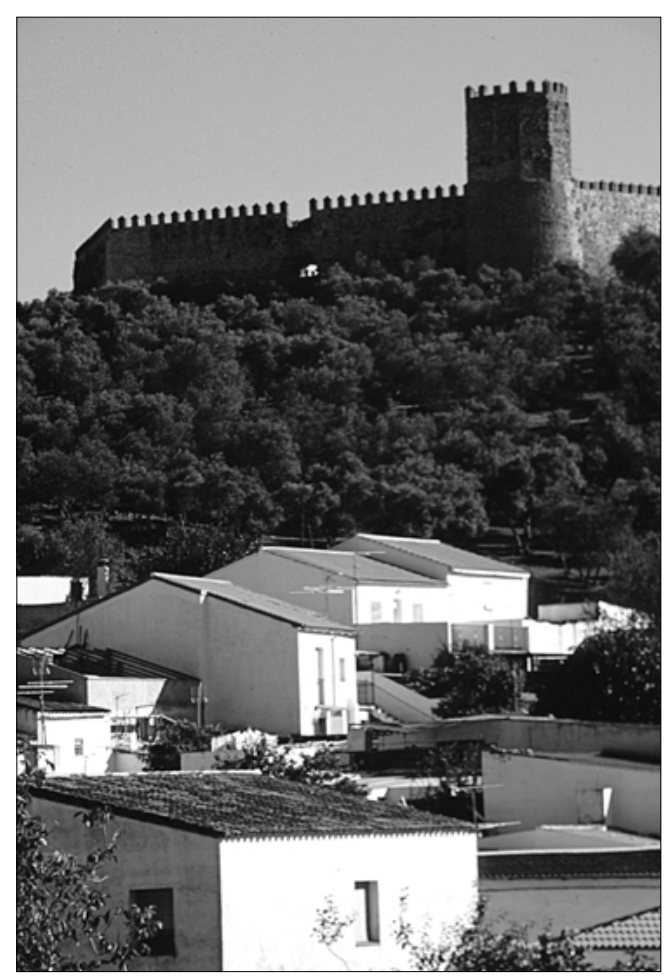


Sevilla, y fue escenario de disputas en la Edad Media, sobre todo en la crisis de sucesión de los Reyes Católicos y entre los linajes de Guzmán y Ponce de León. Los alinienses se levantaron contra las huestes napoleónicas a principios del siglo XIX, su último hito histórico.

Al pasear por sus calles podemos apreciar viviendas que conservan fachadas de estilo mudéjar (siglo $\mathrm{XV}$ ), y renacentista (siglo XVII). Muy popular en el perímetro del casco urbano son la fuente de Santa María, construida en tiempos de Carlos I y la ermita de Nuestra Señora de las Nieves, del siglo XIV, aunque esta última ampliada y remodelada posteriormente (torre y fachada son del siglo XV, la capilla contigua a la cabecera, de 1570; y la última remodelación vino tras el terremoto de 177I). En la actualidad la ermita cuenta con tres naves de cubiertas con bóveda de medio cañón y vaídas en los laterales, y la capilla es de bóveda de nervadura.

No podemos olvidarnos de la capilla de Jesús Nazareno, pequeño recinto de finales del XIX, la ermita de Nuestra Señora de las Angustias (con un grupo escultórico restaurado por Castrillo Lastrucci) y la de San Juan Evangelista, que está cercana al castillo y fue la primera parroquia local.

\section{Cazalla de la Sierra}

Las cercanas cuevas de Santiago atestiguan su origen neolítico, a lo que siguió la Callentum romana, sobre una antigua fortificación cartaginesa y la Castalla árabe. Conquistada por los cristianos en 1247, alcanzó su esplendor en los siglos XVI y XVII, cuando cereales, vinos y aguardientes multiplicaron su importancia y población, que llegó a 10.000 habitantes bien entrado el siglo XX. En el siglo XVI hasta Felipe $V$ pasó dos meses de verano en la villa, en la casa de don Pedro Forero de Guzmán, frente a la fuente del Consejo.

De su esplendor y señorío destaca, camino de Constantina, la Cartuja de Cazalla, fundada en el siglo XV sobre los restos de otra fundación de Jerónimos Observantes (|4|8).

La Cartuja tiene una iglesia con nave cubierta de cañón, espadaña de dos cuerpos y un fresco de San Bruno. Llegó a tener tres claustros, el mayor de 12 celdas. Se cuenta que Pedro el Cruel la utilizó como pabellón de caza.

No menos en cuenta debemos tener la iglesia de la Consolación. El primitivo templo de tres naves se levantó en los siglos XIV y XV, pasando a construirse en 1538 un templo renacentista, y finalmente en el XVIII se cubren con bóvedas de cañón los tramos que restaban por derribar de la primitiva iglesia mudéjar. De este monumento destaca su torre fachada mudéjar, y el extraordinario espacio interno renacentista, que en sus soberbios pilares, coronados por en- tablamiento, reflejan de forma admirable el modelo de la sacristía mayor de la Catedral de Sevilla.

Cualquier viajero que se precie, no puede dejar de pasar por la plaza mayor de Cazalla, donde se encuentran las Casas Capitulares. Hay que citar al menos el exconvento de San Francisco, actualmente transformado en mercado de abastos, y otros conventos, como los de Santa Clara, San Agustín o San Francisco. De la fortaleza almohade perdura una puerta formada por dos arcos de herradura, que hoy da acceso al corral de la iglesia parroquial.

\section{Las Navas de la Concepción}

Fundada en 1557 por los monjes de la orden de San Basilio, llegados de Oriente Medio, cuando el rey Felipe II autorizó crear un municipio dependiente de Constantina. Dos siglos más tarde, en 1764, los frailes basilios, que habían levantado su convento de San Antonio del Valle de Galleguillos, hicieron lo mismo con una parroquia para que los vecinos no se desplazaran a Constantina para bodas y bautizos. La aldea original, Las Navas de los Puercos, por el gran número de gorrinos, se cambió el nombre al actual merced a un decreto de la reina Isabel II, que la independizó de Constantina en 1854.

Su principal monumento es la iglesia de la Purísima Concepción, de la segunda mitad del siglo XVIII. Resalta el retablo mayor neogótico, con imágenes modernas, el púlpito de hierro forjado y una pila bautismal del siglo XV. De entre las imágenes del templo la más importante es un Crucificado del siglo XVI y el grupo escultórico de Santa Ana y la Virgen, del último tercio del XVII.

\section{Constantina}

De origen celtíbero, con el nombre de Sucunmurgi, fue rebautizada por los cartagineses como Lacunumurgi, llamándola más tarde las legiones de Escipión Constantina lulia, dándole acuñación de moneda

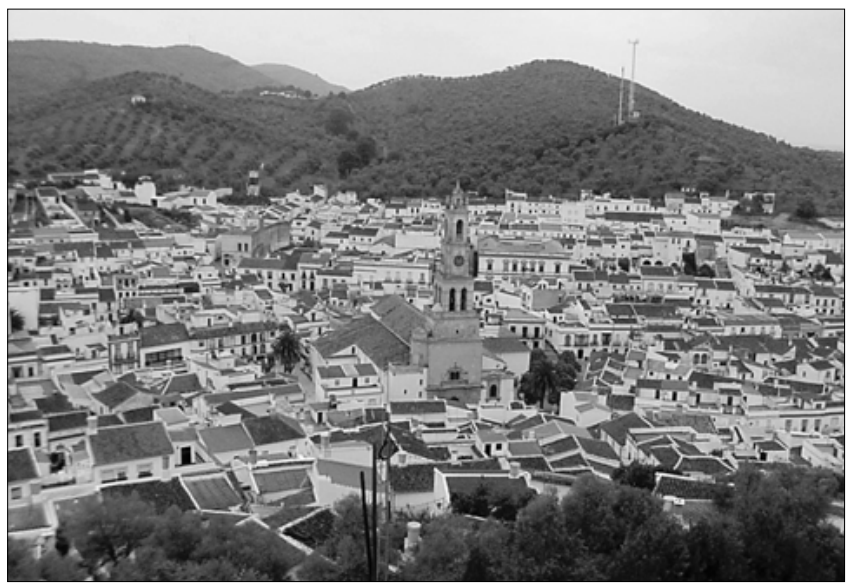




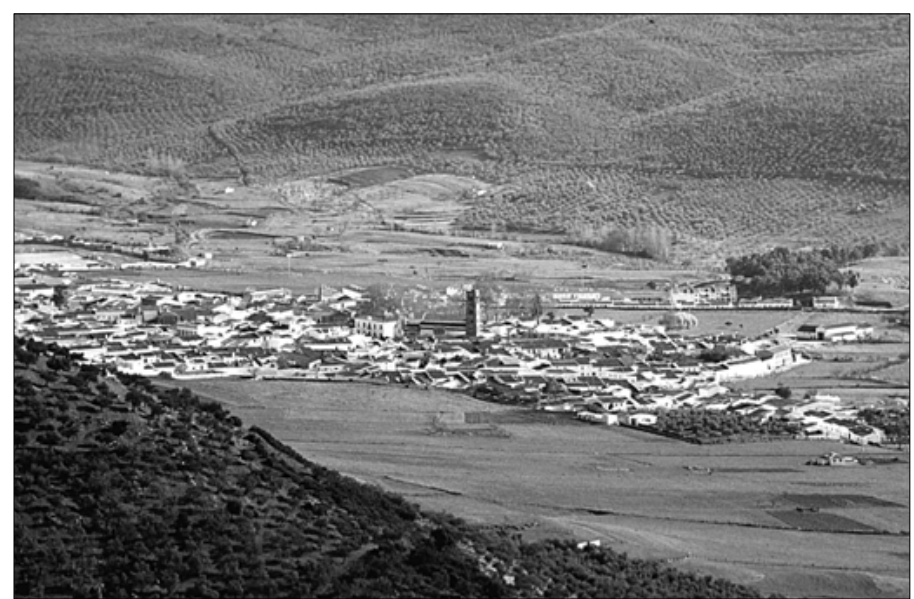

Vista general de Guadalcanal

propia. Conquistada el mismo año que Cazalla, en I 478 pasó de manos nobiliarias a las reales como viIla real. Su la lucha contra Napoleón le concedió el título de ciudad Alfonso XIII.

La arquitectura típica serrana podemos verla en el barrio de la Morería o el de Santa Ana, barrios que podemos localizar si nos asomamos al castillo de origen árabe que se levanta majestuoso en uno de los puntos más altos de la población.

Destaca entre su arquitectura religiosa la ermita de Nuestra Señora de la Hiedra, de la cual queda lo que era el presbítero sin cubierta y dos arcos ojivales. También se conserva la espadaña y la portada de 1570 que presenta marco de medio punto, flanqueado por dos semicolumnas que soportan un friso con triglifos y metopas.

Otras obras de origen con esta mismo origen son la iglesia de Nuestro Padre Jesús, la ermita de Nuestra Señora del Robledo y la iglesia de la Encarnación, esta última con tres naves separadas por arcadas ojivales y portada renacentista de dos cuerpos; su núcleo primitivo es del siglo XVI, interviniendo en su primer cuerpo de campanas Hernán Ruíz en I567, y el resto y el capitel es de Pedro Díaz Palacios.

\section{El Pedroso}

Su origen se atribuye a un asentamiento celta, que después poblaron los romanos con el nombre de Augustóbriga, una mezcla con vocablos celtíberos que significaba ciudad de Augusto. El atractivo de este enclave en sus primeros tiempos fue la gran riqueza minera que ofrecía, la cual ya parece que quedó agotada. Los árabes le dieron más función defensiva, fortificando la villa, aunque no quedan restos apreciables.

En el cercano río del Huesna perduran los restos de lo que fue en el siglo XIX, la próspera fábrica siderúrgica de El Pedroso, unos altos hornos que aprovechaban la fuerza del agua, que tras la fuerte competencia norteña y su lejanía de los circuitos comerciales obligaron a cerrarlos.
Entre los monumentos destaca la iglesia de Nuestra Señora de la Consolación, que conserva una capilla gótica del siglo XV. Es una construcción de sillería, mampostería y ladrillo de una sola nave. Luis de Vargas diseñó su retablo mayor, en el que se haya una imagen de la Virgen con el Niño atribuida a Jerónimo Hernández. Otra interesante muestra del arte de los retablos sevillanos es el altar de la Virgen del Rosario; y también el retablo e Inmaculada de Martínez Montañés, y la mejor obra en madera de Pedro Millán, el Cristo del Buen Fin.

Otro edificio religioso es la ermita de la Virgen del Espino, una obra de estilo mudéjar con añadidos barrocos, como la portada y el remate de la capilla mayor. De 1540 procede la que se considera pieza más valiosa: un crucero elevado sobre gradas con astil de balaustre y capitel de grutescos. En las dos caras de la cruz figuran un Crucificado y una Piedad. Se colocó en un cruce de caminos para cobrar impuestos.

\section{La Puebla de los Infantes}

Tiene su origen prerromano, ha visto pasar casi todas las culturas presentes en la Sierra Norte. Roma se apoderó de lo que para algunos era el enclave celta de Celsita, transformándolo en campamento. Algunos ubican aquí el municipium mulvensis de tan polémica localización. Los visigodos rebautizaron la villa con el nombre de Cañebolo, y languideció este enclave durante el tiempo de los árabes.

Alfonso X "El Sabio", en el repartimiento de 1253 , concedió esta tierra a sus hermanos y otros familiares, otorgando una Carta Puebla de la que viene el nombre de localidad. En el siglo XVII, por enajenaciones y herencias, estos pagos pasaron a manos de un descendiente de aquellos infantes, Luis Jiménez de Góngora y Castilla, que recibió en 1654 el título de vizconde de La Pueble de los Infantes, marquesado a partir de 1716 .

De todo ello ha quedado como muestra la iglesia de Nuestra Señora de la Huerta, de finales del siglo XV y comienzos del $X V I$, y la coquetona $y$ encalada ermita de Santa Ana, mudéjar de finales del XV.

\section{Guadalcanal}

Es un trasiego de culturas, demostrado tanto por los restos neolíticos como por la calzada romana Sevilla-Mérida que por aquí pasaba.

Los romanos aprovecharon los vestigios de la anterior Tereses para refundar la villa de Sisapo. Es posible que en esa época ya recibiera el nombre de Canania o Canalia, a la que los árabes antepusieron Wad como indicativo de la presencia de un río. Los árabes se sirvieron sobre todo de su función defensiva, en un alcázar natural que ya había gozado durante los romanos de una buena conexión mediante calzadas. De esta fortificación de carácter militar 
quedan restos en la iglesia de Santa María de la Asunción: su muro norte.

En I24I los caballeros de la Orden de Santiago, mandados por Rodrigo Iñiguez, tomaron la localidad para la corona de Castilla, por lo que obtuvieron la habitual recompensa de recibir los dominios. Pero fue en el siglo XVI cuando, al descubrirse las minas de plata, adquirió importancia, diluida dos siglos después con el agotamiento del filón.

El patrimonio histórico del pueblo, muy amplio, presenta su exponente más antiguo en la iglesia de Santa María de la Asunción, un edificio gótico-mudéjar construido a partir del resto de un lienzo de la muralla almohade que constituye el muro norte de la iglesia, levantado en el siglo XIV. Obras realizadas en el XVI añaden la magnífica torre rectangular de cinco cuerpos en ladrillo sobre basamento almohade. A la sacristía se accede desde el exterior por una portada en arco de herradura originaria de la fortificación almohade. La capilla sacramental es del siglo XV y posee bóveda de crucería, y las demás capillas laterales se cubren con bóvedas de casetones del siglo XVI. La curiosa pila bautismal es del siglo XIV.

La ermita de Santa Ana de origen mudéjar, de finales del $\mathrm{XV}$ y principios del $\mathrm{XVI}$, consta de una sola nave. La ermita de San Benito es barroca, de la segunda mitad del XVII, con azulejos de Cuenca en la sacristía pertenecientes al siglo XVI.

La iglesia de la Concepción data del primer cuarto del siglo XVII; es de ladrillo y una sola nave cubierta con bóveda de medio cañón. Finalmente, la iglesia de San Vicente tiene su origen en el siglo XVIII, con planta de cruz latina.

\section{El Real de la Jara}

Este pueblo ha motivado mágicas leyendas; se habla que fue la aldea de Tartasia, fundada por Salomón. Muchos siglos después, al parecer, Dios vino en ayuda de los conquistadores cristianos, que no sabían como acometer el asalto hasta que apareció un ciervo y los guió al punto más favorable, intercesión que queda representada en el escudo municipal.

Sea por mediación de la divinidad o de la simple capacidad militar, la árabe Xara fue conquistada por los caballeros de la orden de Santiago en 1247 y, como Almadén, recibió el lema de leal por su participación en la toma de Granada y el título de villa, además del fuero real que le da nombre.

La arquitectura religiosa tiene su mejor exponente en la iglesia de San Bartolomé, mudéjar, con portada de Hernán Ruiz y torre de tres cuerpos. Citar también la ermita de Nuestra Señora de Gracia y el castillo medieval desde el que se domina todo el pueblo.

\section{San Nicolás del Puerto}

Los celtas lo fundaron llamándola Iporci, y los romanos la villa de Fortuumade o Fortunales, que les fue muy útil por el puerto en el que se enclava. Construyeron un magnífico puente sobre el río Galindón. La riqueza de su plata fue explotada por los árabes a partir del siglo VIII, llegando a ganar fama y ser merecedor el paraje del levantamiento de un castiIlo, en tiempos del rey musulmán Aznnar Benajaque, del que pervive una de sus torres. Entre los iporcitanos ilustres se encuentra el religioso San Diego de Alcalá, que tiene un monumento realizado por Antonio Castillo Lastrucci en la plaza de España.

Como edificio emblemático destaca la iglesia de San Sebastián, una construcción mudéjar de una sola nave y sencillo aspecto exterior que data de los siglos $\mathrm{XV}$ y $\mathrm{XVI}$; dentro de ella existe un grupo escultórico de la Piedad realizado por Castillo Lastrucci.

\section{Bibliografía}

Cazalla de la Sierra; naturaleza e historia. Ayuntamiento de Cazalla. 1995.

Colección Los Pueblos de Sevilla. El Correo de Andalucía. 1995.
Andar por la Sierra Norte de Sevilla. Jorge A. Blanco. Penthalon.

Alanís, espacios reales y simbólicos. Antonio García Benítez. Ayuntamiento de Alanís.

Los castillos de la Sierra Norte de Sevilla en al Baja Edad Media. Nuria Casquete. Diputación de Sevilla. 